\title{
EXPRESSÁO DE CASO ARGUMENTATIVO EM AVÁ-CANOEIRO DO TOCANTINS
}

\section{THE EXPRESSION OF THE ARGUMENTATIVE CASE IN AVÁ CANOEIRO}

Ariel Pheula do Couto e Silva (LALLI/UnB, CAPES)

Ana Suelly Arruda Câmara Cabral (LALLI/UnB, CNPq)

\begin{abstract}
Resumo: Tratamos neste artigo da expressão do prefixo de caso argumentativo na língua AváCanoeiro do Tocantins (família Tupí-Guaraní), à luz das análises fundamentais de Rodrigues (1981, 1996 e 2001) sobre os prefixos casuais da língua Tupinambá. Damos sequência à análise de Borges (2006) sobre a expressão do caso argumentativo em Avá-Canoeiro, com base em dados recentes da variedade diatópica do Avá-Canoeiro do Tocantins. Argumentamos em favor da produtividade da flexáo de caso nessa língua, com ênfase no caso argumentativo. Discutimos também a redução dos contextos fonológicos de ocorrência do alomorfe - $a$, o que consideramos prenúncios de sua perda na fala das próximas geraçôes.
\end{abstract}

Palavras-chave: Família Tupí-Guaraní; Avá-Canoeiro; Avá-Canoeiro do Tocantins; Flexão Casual; Caso Argumentativo.

Abstract: In this article we deal with the expression of the argumentative case prefix in AváCanoeiro of Tocantins (Tupi - Guaraní family), in the light of Rodrigues fundamental analysis of the expression of this grammatical category in the Tupinambá language $(1981,1996$ and 2001). We follow the analysis by Borges (2006) on the expression of the argumentative case in Avá- Canoeiro, based on recent data from the diatopic variety of Avá- Canoeiro of Tocantins . We argue in favor of the productivity of the argumentative case in that language, and we also discuss the reduction of phonological contexts triggering its -a allomorph, which we consider a sign of its lost in the speech of the next generations.

Keywords: Tupí-Guaraní family; Avá-Canoeiro; Avá-Canoeiro of Tocantins; Casual inflection; Argumentative case.

\section{Introduçáo}

Tratamos neste trabalho da expressão do caso argumentativo em Avá-Canoeiro do Tocantins, língua pertencente à família Tupí-Guaraní, tronco Tupí (cf. RODRIGUES, 1984/5; RODRIGUES \& CABRAL, 2002). O tema deste artigo foi parcialmente trabalhado em Cabral et alli (2013) e é composto por uma parte relevante de minha dissertação de mestrado (SILVA, 2015, p.110-121) intitulada "Elementos de Fonologia, Morfossintaxe e Sintaxe da Língua Avá-Canoeiro do Tocantins”, defendida em março de 2015. 
A língua Avá-Canoeiro ${ }^{1}$ é atualmente falada por aproximadamente 20 indivíduos (SILVA, 2014a ms; RODRIGUES, 2012 e 2013), divididos geograficamente em dois grupos, no interflúvio Tocantins-Araguaia. Os Avá-Canoeiro do Tocantins se localizam na TI-Avá-Canoeiro ao norte do estado de Goiás, próximo aos municípios de Minaçú e Colinas do Sul; e os Avá-Canoeiro do Araguaia se localizam em três aldeias ao sul do estado de Tocantins, na Ilha do Bananal, na TI-Javaé, além de uma família morando em Palmas (TO) e outra no estado da Bahia. Neste estudo, focamos nossa análise para a expressão do caso argumentativo em Av.C-T.

A descrição dos prefixos casuais das línguas Tupí-Guaraní devem maximamente ao trabalho linguístico pioneiro do professor Aryon Dall'Igna Rodrigues (in memoriam). Em seu artigos "Estrutura do Tupinambá" (2010 [1981]), "Argumento e Predicado em Tupinambá" (2012 [1996]) e "Sobre a Natureza do Caso Argumentativo" (2001), Rodrigues descreve o funcionamento dos cinco prefixos casuais do Tupinambá e a função fundamental do prefixo de caso argumentativo desta língua para a distinçáo morfossintática de argumentos e predicados, podendo estes serem constituídos tanto por nomes quanto por verbos. Ana Suelly Cabral, parceira do prof. Aryon Rodrigues em diversos projetos, dando sequência ao estudo das expressôes do caso argumentativo na família Tupí-Guaraní, publica em 2001 o artigo "Observaçóes sobre a história do morfema -a da família Tupi-Guarani”.

\section{O Caso argumentativo em Tupinambá e na família Tupí-Guaraní}

Segundo Rodrigues (op. cit.), em Tupinambá, tanto nomes quanto verbos podem funcionar como argumentos ou predicados, e nomes sem marcação casual - tanto de caso argumentativo como dos casos de natureza adverbial - funcionam ou como núcleos de predicados existenciais ou possessivos ou como vocativos; enquanto verbos, ao receberem especificação de caso funcionam ou como argumentos, por meio do caso argumentativo, ou como sintagmas adverbiais, por meio de casos locativos (RODRIGUES, 2001a, p.105).

Nesta língua, há a ocorrência de cinco prefixos casuais, que formam um paradigma, que são os prefixos de caso que codificam uma função adverbial: (a) locativo pontual (-pe - ipe); (b) caso locativo difuso ( $-\beta o-$

\footnotetext{
${ }^{1}$ Faremos referência, ao longo desta dissertação, aos Avá-Canoeiro como Av.C e aos AváCanoeiro do Tocantins como Av.C-T.
} 
-i $\beta$ o); (c) caso locativo situacional (-i); e (d) caso locativo translativo (-amo $\sim$-ramo); e o prefixo casual de caso argumentativo $(a-\sim \varnothing$-), que codifica a função argumental na língua. Em contraste com a expressão de caso, o autor (2012 [1996], p.96) considera a existência de um caso náo marcado, o caso vocativo $(-\varnothing)$. Apresentamos abaixo a tabela de Rodrigues (2001, p.108 grifos do autor) como forma de ilustrar o paradigma da flexão casual em temas nominais:

\begin{tabular}{|c|c|c|c|}
\hline & -ajúr-'pescoço' & -kuiád- 'cintura' & -jị̂a - 'coração' \\
\hline ARG. & ajúr-a & ku?á-Ø & jị̂ã- Ø \\
\hline Transl. & ajúr-amo & kulá-ramo & jị̂ã-namo \\
\hline Loc. PONT. & ajúr-ipe & ku?á-pe & jịã-me \\
\hline LOC. DIF. & ajúr-ißßo & ku?á-ßo & jîā-ßo \\
\hline Loc. SIT. & ajúr-i & ku?á-j & jîaá-j \\
\hline
\end{tabular}

A função argumental, para o autor, pode ocorrer tanto com nomes quanto com verbos, abarcando as principais funçóes gramaticais: sujeito de verbos transitivos (A) e intransitivos (S), objeto direto (O), objeto de posposições e determinantes de sintagmas nominais. Seguem abaixo alguns exemplos extraídos de Rodrigues (2001 e 2012 [1996]):

Como argumentos de predicado

$\begin{array}{llll}\text { tapi?ír-a } & \text { o-so } & \text { ók-a } & \varnothing \text {-kotí } \\ \text { vaca-ARG } & 3 \text {-ir } & \text { casa-ARG } & \mathrm{R}^{1} \text {-para.o.lado.de }\end{array}$

"as vacas foram para a banda das casas"

kwesé pajé- $\varnothing \quad$ ma?easíßor-a $\varnothing$-sußán-i

ontem pajé-ARG o.doente-ARG $\mathrm{R}^{1}$-chupar ritualmente-IND.II

"ontem o feiticeiro chupou ao enfermo"

sje r-úß-a t-oßajár-a ja- $\varnothing$ - $2 u ́$

$1 \quad \mathrm{R}^{1}$-pai-ARG $\quad \mathrm{R}^{4}$-adversário-ARG 3- $\mathrm{R}^{2}$-comer

"os contrários comeram meu pai" 


\section{Como objetos de posposição}

sje r-orí-katu

ne r-úr-a

$\varnothing$-ri

$1 \mathrm{R}^{1}$-alegria-bondade

$2 \mathrm{R}^{1}$-vir-ARG

$\mathrm{R}^{1}$-por

"eu me alegro muito pela vinda de você" (ou: por você ter vindo, ou: porque você veio)"

\section{Em determinantes de sintagmas nominais}

jąwar-a?́r-a

onça-filho-ARG

"filhote de onça"
ja?war-a
r-a?́ŕr-a
onça-ARG
$\mathrm{R}^{1}$-filho-ARG
"o filhote da onça”

O caso argumentativo é encontrado na maioria das línguas da família Tupí-Guaraní, ocorrendo, de maneira geral, ou por meio dos alomorfes $-\emptyset$ diante de vogal e - $a$ diante de consoante ou por meio de $-a$ diante de vogais e consoantes e $-\emptyset$ diante de /a/ (cf. CABRAL, 2001).

\section{O caso argumentativo em Avá-Canoeiro}

Para Borges (2006, p.118) o caso nuclear "identifica uma palavra como pertencente à classe "nome" na língua", marcando as funçôes de nome em: "sujeitos de verbos intransitivos ativos e descritivos (Sa e So)"; "sujeitos de verbos transitivos (A)"; "objetos diretos (O)"; "complementos da cópula $e k o$ iko 'ser, estar"; "modificadores (possuidores) em construçôes possessivas"; "objetos das posposiçóes"; e em "predicados nominais". Realizase, nesta língua, por meio dos alomorfes $-a$ ou $-\emptyset$, "seguindo tanto nomes terminados em consoantes [...] quanto vogais" (op. cit., p.118-119). Abaixo reproduzimos alguns exemplos da autora, mantendo a numeração e glosa original.

${ }^{2}$ Seki (2000, p.107-109) considera o "caso argumentativo" de Rodrigues (1996, 2001a) como "caso nuclear". Este serviria, na língua Kamaiurá, para "relacionar o nome a outro elemento na locuçẫo, ou ao predicado na oração". Expressaria, nessa língua, as funçôes de "sujeito de predicados verbais e não-verbais"; "objetos de verbos e posposiçôes; modificador (possuidor) na locução genitiva; complemento de cópula; predicado nominal”. 
Sujeitos de verbos intransitivos ativos
(382a) Sa
V
enem-a o-wewe
besouro-cn 3sgSa-voar
[enẽmə $\quad \mathrm{o}^{\prime} \mathrm{G}^{\mathrm{w}} \mathrm{eG}^{\mathrm{w}} \mathrm{e}$ ]
'O besouro está voando' (BORGES, 2006, p.119)

Sujeitos de verbos intransitivos descritivos

(382b) So

mae-b-o-a

caça-rel-carne-cn

['mae'воә

'A carne está crua' (BORGES, 2006, p.119)
V

i-ріва

3So-estar, ser crua

I'p $\mathrm{p}^{\mathrm{i}} \mathrm{i}$ í]

Sujeitos de verbos transitivos

(384a) A

V

$\mathbf{P}$

moj-a

o-mokon

abakare- $\emptyset$

cobra-cn

3sgA-engolir

galinha-cn

['mozo

o'moqõni

aba' $\mathrm{k}^{\mathrm{h}}$ arI]

'A cobra engoliu a galinha' (BORGES, 2006, p.119)

Objetos diretos

(385a) $\mathbf{P}$

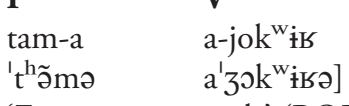

'Eu amarrei a corda' (BORGES, 2006, p.119)

Complementos da cópula eko - iko 'ser, estar'

(388a) cópula

o-iko

3sg-ser estar

[o'iqu

'Ela (Makaquira) é minha irmã' (BORGES, 2006, p.120)

\section{complemento}

$\mathrm{t} \int \mathrm{i}=\emptyset$-pikir-a

1 poss=rel-irmá mais nova-cn

,t $t$ Ipi't $k^{\text {hir }}$ ir $]$ 
Modificadores (possuidores) em construçöes possessivas

(389a) Possuidor

Núcleo

i-memís-a

r-akan

3-filho-cn

rel-cabeça

[ĩ'mẽmísə

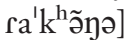

'A cabeça do filho dela (Tuia)' (BORGES, 2006, p.120)

Objetos de posposiçöes

(390a) Sa

tapira- $\emptyset=$ ete

anta-cn=part

$\left[t_{1}{ }^{\mathrm{h}}\right.$ apisit $\mathrm{I}^{\mathrm{h}} \mathrm{e}$

'A vaca entrou na terra (lama)' (BORGES, 2006, p.120) adj

ij-a pupe

terra-cn posp

iz $\left.3 \partial^{\prime} \quad \mathrm{p}^{\mathrm{h}} \mathrm{upe}\right]$

Predicados nominais

(391a) Sujeito

putfidzawa

nome próprio

'Putdjawa é minha irmã' (BORGES, 2006, p.120)
Predicado

$\mathrm{t} \int \mathrm{i}=\emptyset$-pikir-a

1 poss=rel-irmã-CN

Para Borges (op. cit., p.121), o morfema - $a$ estaria se lexicalizando em determinadas palavras, preferencialmente em temas dissilábicos ou trissilábicos, e palavras terminadas em $r$, estando a cristalizaçáo relacionada ao deslocamento do acento da língua para a penúltima sílaba. Reproduzimos abaixo quadro da autora (op. cit.) para palavras do Avá-Canoeiro ilustrativas desse processo. 
Quadro I - Palavras do Av.C com lexicalizaçáo do morfema $\{$-a $\}$

\begin{tabular}{|c|c|c|c|}
\hline PTG & $A v-C$ & Glosas & Realização fonética \\
\hline 1.*tapi?ir & tapira & 'anta' & {$\left[\mathrm{t}^{\mathrm{h}} \mathrm{a}^{\prime} \mathrm{p}^{\mathrm{h}} \mathrm{i}:\ulcorner\partial]\right.$} \\
\hline 2. *iar & дака & 'canoa' & ['їәәгә] \\
\hline 3. *ok & oka & 'casa' & ['o:kə] \\
\hline 4.*aman & amana & 'chuva' & ['ว̃:mว̃nə] \\
\hline 5. *po?ir & роіка & 'contas (colar)' & ['p $\mathrm{p}^{\mathrm{h}}$ о:і́ьә] \\
\hline 6.*aits & ать́ & 'filho' & ['а:їьә] \\
\hline 7. ${ }^{*}$ potis & potisa & 'flor' & ['p $\mathrm{p}^{\mathrm{h}}$ эttisə] \\
\hline 8.*eir & еіка & 'mel' & ['е:јьә] \\
\hline 9. *er & era & 'nome' & ['е:гә] \\
\hline 10.* jawar & јашаьа & 'cachorro' & ['3a:Gºsəo] \\
\hline $11 . * \operatorname{tsa} \beta$ & -awa & 'plumagem' & ['a:wə] \\
\hline
\end{tabular}

No entanto, a autora (op. cit., p.123) considera que a marca - $a$ é obrigatória quando da necessidade de se diferenciarem sintagmas nominais possessivos e oraçóes possessivas, conforme os exemplos reproduzidos abaixo.

\section{Sintagmas Nominais Possessivos}

(395a) t $\int \mathrm{i}=\mathrm{r}-\mathrm{etam}-\mathrm{a}$

$$
\begin{aligned}
& {\left[1 \mathrm{t} \int \mathrm{Ire} \mathrm{t}^{\mathrm{t}} \mathrm{\textrm {z }} \tilde{\mathrm{m} ə} \mathrm{]}\right.} \\
& 1=\mathrm{REL}-\mathrm{casa}-\mathrm{CN} \\
& \text { 'minha casa' (BORGES, 2006, p.24) }
\end{aligned}
$$

(396a) tapira- $\emptyset=$ ete

$\left[\mathrm{t}^{\mathrm{h}} \partial_{1}\right.$, $\operatorname{sir}^{\mathrm{l}} \mathrm{t}^{\mathrm{h}} \mathrm{e}$ anta-CN=part

$\emptyset$-memís-a 'те̃тівә] REL-filho-CN

'A vaca tem bezerrinhos (filhotes)' (BORGES, 2006, p.24) 
(397a)t $\int \mathrm{i}=\mathbf{c}-\mathrm{etam}-\varnothing$

$\left[, t \int \operatorname{Ire}^{\mathrm{t}} \mathrm{t}^{\mathrm{h}} \tilde{\mathrm{\partial}} \mathrm{m}\right]$

$1=$ REL-casa-CNM

'eu tenho casa'(BORGES, 2006, p.24)

(398a) tapira- $\emptyset$-=ete

$\left[\mathrm{t}^{\mathrm{h}} \partial\right.$, pir I $\mathrm{t}^{\mathrm{h}} \mathrm{e}$

i-memis- $\varnothing$

anta-CN=part

I'mе̃тік ]

3-filho-CNM

'A vaca tem bezerrinhos (filhotes)'(BORGES, 2006, p.24)

Ao trabalharmos novos dados do Av.C-T, sobretudo relativas às faixas I e II (falantes remanescentes do contato) ${ }^{3}$, observamos que o sufixo casual de caso argumentativo, referido por Borges (op. cit.) como sufixo de caso nuclear, ocorre normalmente na marcação de argumentos de base verbal ou nominal; em construçóes possessivas marcando o determinante; em oraçóes existenciais e equativas marcando um dos constituintes; e em objetos de posposiçóes. Os nomes, nesta língua, funcionam ou como predicados ou como vocativos sem marcação de flexão de caso. E os verbos, com a marcação de caso argumentativo, funcionam como argumentos na oração.

$\mathrm{Na}$ sequência, constam alguns exemplos que ilustram a expressão dos alomorfes $-\emptyset$ e $-a$ do caso argumentativo tanto na marcação de argumentos de temas nominais (exemplos (1) a (3); (5) a (18)) quanto temas verbais (exemplos (19) a (22)); marcando objetos de posposição (exemplos (4); (23) a (26)); e marcando ambos os sintagmas nominais de oraçóes equativas (exemplos (27) e (28)).

\section{Alomorfe $-\emptyset$}

(1) talew- $\emptyset$ в-upia- $\varnothing$

traíra-ARG $\mathrm{R}^{1}$-OVO-ARG

'o ovo de traíra'

walew- $\emptyset$ i-kupe

guariba-ARG $\mathrm{R}^{2}$-de.costas

'(o) guariba (está deitado) de costas'

\footnotetext{
${ }^{3}$ Para a descrição de elementos da fonologia da língua Av.C-T, Silva (2015, p.26-27) distingue quatro faixas geracionais de falantes Av.C-T: (I) de 60 a 80 anos; (II) de 40 a 60 anos; (III) de 20 a 30 anos; e (IV) de 0 a 5 anos.
} 
(3) akaju-i- $\varnothing$

cajú-ATEN-ARG

' cajúzinho-do-cerrado'

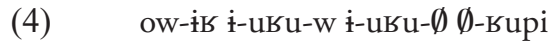

3-ir água-INTENS-LOC água-INTENS-ARG R ${ }^{1}$-POSP(perlat)

'ele vai no rio cheio, pelo rio cheio'

(5) t ti tố t t i l-epusu- $\emptyset$ a-itik

1 FOC 1=' $\mathbf{R}^{1}$-bolsa/cesto-ARG 1-tirar

'eu, eu joguei fora (tirei) minha mochila (de cotia)'

Alomorfe - a

(6) t ti в-араь-а

$1=\mathrm{R}^{1}$-arco-ARG

'(o) meu arco'

(7) tapil-a

anta-ARG

' anta'

(8) i-memis-a

$\mathrm{R}^{2}$-filho(ego.feminino)/estar.grávida-ARG

'o estar grávida de(la)'

(9) i-men-a

$\mathrm{R}^{2}$-marido-ARG

' marido de(la)'

(10) i-ito-a

$\mathrm{R}^{2}$-velho-ARG

a velhice (da calça)'

(11) i-kiw-a

$\mathrm{R}^{2}$-piolho-ARG

'piolho dele'

(12) i-nim-a

$\mathrm{R}^{2}$-fedor-ARG

'o fedor (do gambá)' 
(13) $\quad \mathrm{t} \int \mathrm{i} \emptyset$-kiw-a

$1=\mathrm{R}^{1}$-piolho-ARG

'meu piolho'

(14)

$\begin{array}{ll}\text { mae pa } & \text { ekoj-a } \\ \text { coisa/animal perg } & \text { DÊIT-ARG } \\ \text { 'o que é isto?' } & \end{array}$

(15)

mail-a tó ow-el-eko

Branco-ARG FOC 3-C.C.-estar.em.mov

'o Branco faz (outro) estar consigo', 'o Branco tem esposa'

(16) ab-a o-ike

Sol-ARg 3-entrar

'(o) Sol entrou (se pos)'

(17)

$\begin{array}{ll}\text { moj-a } & \text { o-t } \int \mathrm{u} \\ \text { cobra-ARG } & 3 \text {-morder }\end{array}$

'a cobra mordeu (o rato)'

(18)

$\begin{array}{ll}\text { iw-a } & \text { o-pilok } \\ \text { terra-ARG } & \text { 3-descascar } \\ \text { 'descasca (ilumina) a terra' (com referência ao brilho da lua) }\end{array}$

Argumentos de base verbal

(19) ne в-uj-a

$2=\mathrm{R}^{1}$-ir-ARG

'o ir de você'

(20) Maria- $\emptyset \quad$ t $\int \mathrm{i} \emptyset$-kutuk-a

Maria $\quad 1=\mathrm{R}^{1}$-furar-ARG

'Maria me furou (com a agulha de injeção)'

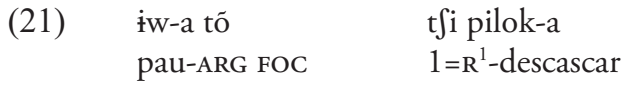

'o pau (a lenha), o meu descascar (dele)' 
Em objetos de posposição
Pãtfeo i-akan-ał
koem-a ь-upi
Pãt $\int e o \quad R^{2}$-cabeça-dor
manhā/madrugada-ARG $\mathrm{R}^{1}$-POSP(PER- LAT)
'Páxe'o teve dor de cabeça pela manhã/madrugada'

$$
\begin{aligned}
& \text { ne tô ele-iko ok-a } \emptyset \text {-pupe } \\
& 2 \text { FOC 2-estar.em.mov. casa-ARG } \mathrm{R}^{1} \text {-POSP(dentro) }
\end{aligned}
$$

$$
\begin{aligned}
& \text { o-mae awa- } \emptyset \text { l-e } \\
& \text { 3-olhar pessoa-ARG }{ }^{1} \text {-POSP(com.respeito.a) } \\
& \text { 'ele olhou com respeito à gente' } \\
& \begin{array}{ll}
\text { a-juka } & \text { ita- } \emptyset \emptyset \text {-po } \\
\text { 1-matar } & \text { pedra-ARG R}{ }^{1} \text {-POSP(INSTRUM) } \\
\text { 'eu matei (a cobra) com a pedra (utilizando um estilingue)' }
\end{array}
\end{aligned}
$$

Oraçôes equativas

$$
\begin{array}{ll}
\text { mukura- } \emptyset & \text { i-akain-a } \\
\text { mucura/gambá-ARG } & \mathrm{R}^{2} \text {-fedor-ARG } \\
\text { 'o gambá tem fedor' } &
\end{array}
$$

$$
\begin{array}{ll}
\text { maniok-a } & \text { i-pilik-a } \\
\text { mandioca-ARG } & \mathrm{R}^{2} \text {-casca-ARG } \\
\text { 'a casca de mandioca' } &
\end{array}
$$

Em Av.C-T, assim como na língua Tupinambá, quando o caso argumentativo não é utilizado em temas nominais, estes funcionam ou como predicados de base nominal (exemplos (29) a (38) abaixo) ou como vocativos (exemplos (39) a (41) abaixo).

\section{Oraçōes existenciais e possessivas}

(28) awa- $\emptyset$ l-emetakan gente-ARG $\mathrm{R}^{1}$-bacia-osso 'é osso da bacia de gente' 
(29) awa- $\emptyset$-pina-kan

gente-ARG $\mathrm{R}^{1}$-coluna.vertebral

'é coluna vertebral de gente'

(30) janu- $\emptyset \emptyset$-kiaw

aranha-ARG $\mathrm{R}^{1}$-rede/teia

'é teia de aranha'

(31) awã- $\emptyset \emptyset$-kam

gente-ARG $\mathrm{R}^{1}$-peito

'é peito de gente'

(32) abakali- $\emptyset$ в-о а

galinha-ARG $\mathrm{R}^{1}$-carne DÊIT

'essa é carne de galinha'

(33) awa- $\emptyset$ l-ea

gente-ARG $\mathrm{R}^{1}$-olho

'é olho de gente'

(34)

$$
\begin{aligned}
& \text { t } \int \mathrm{i} \emptyset \text {-po- } \emptyset \quad \emptyset \text {-ai-te } \\
& 1=\mathrm{R}^{1} \text {-mão-ARG } \\
& \text { '(aí) a minha mão tem muita dor' }
\end{aligned}
$$

(35)

$$
\begin{array}{ll}
\text { ok-a } & \text { i-jia-te } \\
\text { casa-ARG } & \mathrm{R}^{2} \text {-ser.alto-GEN }
\end{array}
$$

'a casa é alta' (em referência à uma Igreja vista em imagem de livro)

$(36)$

$$
\begin{array}{ll}
\text { jatit-a } & \text { i-ajape } \\
\text { caracol-ARG } & \mathrm{R}^{2} \text {-casca } \\
\text { 'é casca de caracol' } &
\end{array}
$$

(37) i-akain

$\mathrm{R}^{2}$-fedor

'é fedorento' 
Vocativo

mat $\int a$ na ne $\emptyset$-ai-te-j tô

Mat $\int \mathrm{a} \quad$ NEG $2=\mathrm{R}^{1}$-ter.dor-GEN-NEG FOC

'Mat $\int a$, você não está sentindo dor?'

Ariel $\quad n$ ele-u-j pana mae

Ariel NEG 2-comer-NEG FRUST coisa

'Ariel, você não tem comido nada'

$$
\begin{aligned}
& \text { t } \int \mathrm{i} \emptyset \text {-milaj } \\
& 1 \mathrm{R}^{1} \text {-neta } \\
& \text { 'minha neta! (Mat } \int a \text { falando para Niwatima)' }
\end{aligned}
$$

Mesmo com o caso argumentativo ainda produtivo, os contextos fonéticos em que - $a$ se expressa, em Av.C-T, estão se reduzindo por conta de alguns temas terminados em consoantes serem reinterpretados como terminados por vogais. Em Av.C-T há um processo fonético de inserção vocálica (cf. BORGES, 2006, p.94; SILVA, 2015, p.69-71) (a) [ə], [в] ou [i] ao final de temas terminados pelas consoantes nasais $/ \mathrm{m} / \mathrm{e} / \mathrm{n} / \mathrm{e}$ consoantes não anteriores, como $/ \mathrm{k} / \mathrm{e} / \mathrm{s} /$; e (b) [ə], [e] ou [I] diante de temas terminados em /1/. Com isso, além de - $a$ năo ocorrer diante de vogais e de /w/, - $a$ concorre com a inserção de vogais ao final de temas terminados por consoantes nasais e não-anteriores. Conforme também ocorre em outras línguas Tupí-Guaraní, o morfema - $a$ em Av.C-T pode sofrer elipse diante de palavra iniciada por vogal (exemplos (17) e (18)), assim como temas terminados por vogal a perdem diante de constituintes iniciados por vogais (cf. BORGES, 2006, p.96-97; SILVA, 2015, 68-69).

\section{Mudanças na expressáo de caso argumentativo na família Tupí-Guaraní}

Quanto às mudanças ocorridas em línguas Tupí-Guaraní em relaçáo ao morfema $-a$, de caso argumentativo, já foi proposto que a queda ou o enfraquecimento deste estaria relacionado à perda das consoantes finais da língua, como ocorreu com as línguas Wayampí, Guaraní Paraguaio e Guaraní antigo (cf. CABRAL, 2001b). No entanto, Cabral (op. cit.) observa que o Suruí do Tocantins (pertencente ao mesmo subramo que o Av.C-T subramo IV), mesmo mantendo consoantes finais, passou a enfraquecer o uso do morfema - a. Monserrat (1985 apud CABRAL, op. cit.) comenta que os Suruí mais velhos mantinham o uso de $-a$ tanto em temas terminados 
por consoante como por vogais, à exceçáo dos temas terminados pela vogal final $/ a /$, contexto em que esse sufixo seria $-\emptyset$. Entretanto, os mais novos não estariam utilizando - $a$ após vogais e aproximantes (exemplos em (42)) e estariam fazendo o uso de um glide vocálico [ə] em flutuação com [a] em temas terminados por sons não-vocálicos (exemplos em (43)) ou diante de $/ \mathrm{r} /$, contexto em que é mais frequente (exemplos em (44); ou ainda utilizando este glide para formas que, historicamente, não poderiam ter - $a$ (exemplos em (45)). Reproduzimos abaixo os exemplos de Monserrat (1985 apud CABRAL, op. cit.), com nossa numeração.

$\begin{array}{lll}\text { (a) } & \text { tatupéw } & \text { 'tatu-peba' } \\ \text { (b) } & \text { moj } & \text { 'cobra' } \\ \text { (c) } & \text { sapuhú } & \text { 'xexéu } \\ \text { (d) } & \text { sakaré } & \text { 'jacaré' }\end{array}$

$\begin{array}{lll}\text { (a) wainóm - wainómə } & \text { 'beija flor' } \\ \text { (b) tukán - tukánə } & \text { 'tucano' } \\ \text { (c) } & \text { wyratí́ - wyratínə } & \text { 'garça' } \\ \text { (d) } & \text { ó - óyə } & \text { 'casa' }\end{array}$
(a) sawár - sawárə - sawára
'onça'
(b) wyra?ýr - wyra?ýrə - wyra?ýra
'galinha'
(a) uPárə
'caiu'
(b) upáwə
'acabou'
(c) mémə
'fedido'
(d)
aesáyə
'vi'

Segundo Cabral (2001, p.153), essa mudança diageracional do sufixo de caso argumentativo em Suruí sugere que "alguma mudança relativa às possibilidades predicativas e argumentais de nomes, descritivos e verbos esteja em processo nessa língua", sendo que "a perda do morfema - a pode ocorrer através de duas ou três geraçôes".

A mudança ocorrida em Suruí do Tocantins é esclarecedora quanto à expressão do sufixo de caso argumentativo $-a$ em Av.C-T. De forma semelhante ao Suruí, o Av.C-T faz uso da inserção de sons vocálicos após temas terminados por consoantes, sendo que estes poderáo passar por um processo de reinterpretação de sua forma ao longo das próximas geraçóes, ao incluírem-se essas vogais como forma da raiz desses temas. 
Quanto ao contexto Suruí mais frequente para a inserção do glide sonoro [ə], isto é, após /r/, é interessante notar também que os fonemas / $/ \mathrm{b} /$ e /1/ do Av.C-T, de forma geral, vieram de um proto */r/ do PTG, assim

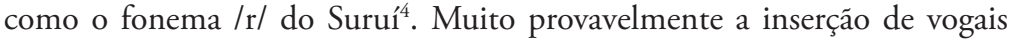
esteja associada à manutenção dessas consoantes finais, sobretudo no Av.C, uma vez que seu padrão acentual mudou da última sílaba, em PTG, para a penúltima. Em outras línguas do subramo IV, como o Asuriní do Tocantins, alguns processos morfofonêmicos mantém a realização de consoantes finais e em fronteira de morfema (CABRAL et al., 2012, p.27):

1) $/ \mathrm{w} /, / \mathrm{r} / \mathrm{e} / \mathrm{k} /$ mudam respectivamente em $/ \mathrm{m} /, / \mathrm{n} /, / \mathrm{g} /$ diante de silêncio (-ów 'pai' $\rightarrow$-óm, -poî́r 'colar' $\rightarrow$-poî́n, -kotók 'picar' $\rightarrow$-kotón).

2) $/ \mathrm{k} /$ muda também em $/ \mathrm{y} /$ em fronteira de morfema diante de sufixos flexionais (e- '2sg.'+ -aṕ́ k 'sentar-se'+ -eme 'proibitivo' $\rightarrow$ e-apín-eme 'não te senta!') e derivacionais (-apł́́k + -eté 'intensificador' $\rightarrow$-aṕ́n eté 'sentar-se bem'), exceto diante do sufixo de gerúndio ( $-a p$ í $k+-a$ 'gerúndio' $\rightarrow-a p$ úka 'sentando-se') e os sufixos nominalizadores de agente e de circunstância $(-a p$ ík $k$ - -áw 'nom' + -a 'arg' $\rightarrow-a p$ íkáwa 'lugar de se sentar').

3) $/ \mathrm{w} / \mathrm{e} / \mathrm{r} / \mathrm{mudam}$ respectivamente $\mathrm{em} / \mathrm{p} / \mathrm{e} / \mathrm{t} / \mathrm{em}$ fronteira de morfema diante do sufixo do gerúndio e dos nominalizadores de agente e de circunstância (-Rár 'cair' + -a 'gerúndio' $\rightarrow$-Ráta 'caindo').

Cabral (2001, p.141), comenta ainda que "as línguas que não apresentam reflexos do PTG ${ }^{*}-a$ possuem a particularidade de terem também perdido o sufixo de 'mesmo sujeito I', e a maioria delas perdeu também consoantes finais". No caso do Av.C-T, o sufixo de gerúndio passou a ter, por conta da mudança de acento, um alomorfe $-\emptyset$ tanto diante de vogais quanto de consoantes, o que pode indicar uma mudança em curso (cf. SILVA, 2015, p. 95-99).

\section{Algumas consideraçóes finais}

Notamos, a partir do exposto, que o sufixo casual de caso argumentativo - $a$ é produtivo em Av.C-T, marcando a função argumental tanto de nomes quanto de verbos, ocorrendo nos determinantes de sintagmas nominais e verbais e em objetos de posposição. No entanto, por conta da mudança no padrão acentual da língua, houve um processo fonológico de inclusão de sons vocálicos em temas terminados por vogais nasais ou consoantes

\footnotetext{
${ }^{4}$ Para a mudança histórica do rótico */斤 / > / / em Avá-Canoeiro, veja-se Borges (2006, p.59-

63) e (SILVA et alli, 2016, em preparação).
} 
não-anteriores, como / / / e /l/, como uma estratégia de manutenção das consoantes finais, mantendo um padrão silábico $\mathrm{CV}$. Estes sons vocálicos finais competem para a diminuição dos contextos fonológicos de ocorrência do caso argumentativo, o que pode acarretar, ao longo das próximas geraçóes ou na geração dos mais jovens, a perda desse morfema na língua.

\section{Referências Bibliográficas}

BORGES, Mônica Veloso. Aspectos Fonológicos e Morfossintáticos da LínguaAvá-Canoeiro (Tupi-Guarani). Tese (Doutorado em Lingüística.) IEL-UNICAMP, 2006.

CABRAL, Ana Suelly Arruda Câmara. Observaçóes sobre a história do morfema -a da família Tupi-Guarani. In: F. Queixalós. (Org.). Des noms et des verbs en tupi-guarani: état de la question. 1ed.Muenchen: LIMCOM EUROPA, 2001b, v. 1, p. 133-162.

CABRAL, Ana Suelly A. C. ; LOPES, Jorge D. ; SILVA, Ariel P. C.; SOUSA, Suseile A. Esboço gramatical do Asuniní do Trocará. In: CABRAL, Ana Suelly et al. (Orgs.). Contribuiçóes para o Inventário da Língua Asuriní do Tocantins: Projeto Piloto para a Metodologia Geral do Inventário Nacional da Diversidade Linguística. Brasília, DF: Laboratório de Línguas Indígenas/UnB, 2012.

CABRAL, Ana Suelly A. C.; SILVA, Ariel P. do C. e; SOUSA, Suseile A.. Expressão do caso argumentativo em três línguas Tupí-Guaraní: Asuriní do Tocantins, Avá-Canoeiro e Zo'é. In: SILEL, v.3, n.1. Anais. Uberlândia: EDUFU, 2013. Disponível em: <http://www.ileel.ufu.br/anaisdosilel/wpcontent/uploads/2014/04/silel2013_1900.pdf>. Acesso em: jan./2016.

RODRIGUES, Aryon D.. A estrutura do Tupinambá. A estrutura do Tupinambá [1981]. In: CABRAL, Ana Suelly Arruda Câmara; RODRIGUES, Aryon Dall'Igna (Org.). Línguas e Culturas Tupí 2. Campinas, SP: Curt Nimuendajú; Brasília, DF: LALI/UnB, 2010. p. 167203.

. Relaçóes Internas na Família Linguística Tupi-Guarani. Revista de Antropologia, São Paulo, v. 27, p. 33-53, 1985.

Argumento e Predicado Em Tupinambá. Boletim da Associaçáo

Brasileira de Linguística, v. 19, p. 57-66, 1996. 
. Sobre a natureza do caso argumentativo. In: F. Queixalós. (Org.).

Des noms et des verbes en tupi-guarani: état de la question. led. Munique: LINCOM Europa, 2001a, v. , p. 103-114.

RODRIGUES, Aryon Dall'Igna; CABRAL, Ana Suelly Arruda Câmara. Revendo a classificação interna da família Tupí-Guaraní. In: CABRAL, A. S. A. C., RODRIGUES, A. D. (Orgs.). Línguas indígenas brasileiras: fonologia, gramática e história. Tomo I. Belém: UFPA, 2002. p. 327-337.

RODRIGUES, Patrícia de M. Relatório Circunstanciado de Identificaçáo e Delimitação da Terra Indígena Taego Áwa. 2012 (não publicado).

. Os Avá-Canoeiro do Araguaia e o tempo de cativeiro. In: Anuário Antropológico/2012-I, 2013, p. 83-137. Disponível em: <http://www. dan.unb.br/images/pdf/anuario antropologico/Separatas\%202012 I/Os Ava-Canoeiros do Araguaia e o tempo de cativeiro \%20Patricia.pdf $>$. Acesso em: jan. 2016.

SEKI, Lucy. Gramática do Kamayurá, língua Tupi-Guarani do Alto Xingu. Campinas: Editora da Universidade Estadual de Campinas, 2000.

SILVA, Ariel Pheula do Couto e. Relatório Anual (2012/2013) do projeto Assessoria Linguística Junto aos Avá-Canoeiro. Brasília, 2014a, m/s.

Elementos de Fonologia, Morfossintaxe e Sintaxe da Língua Avá-Canoeiro do Tocantins. Dissertação (Mestrado). Brasília: Universidade de Brasília/Instituto de Letras/Departamento de Linguística, Português e Línguas Clássicas, 2015.

SILVA, Ariel Pheula do Couto; LUCERO, Jorge Carlos; CABRAL, Ana Suelly Arruda Câmara; COUTO, Fábio Pereira. The Uvularization of the Proto-Tupi-Guarani ${ }^{*} \mathrm{~s}$ > $\mathrm{s}$ in Avá-Canoeiro language (Tupí-Guaraní). Leuuwarden/Ljouwert: Fryske Akademy, 2016. Mimeo.

Expressão de caso argumentativo em Avá-Canoeiro do Tocantins Ariel Pheula do Couto Silva Ana Suelly Arruda Câmara Cabral Recebido em 05/07/2015 Aprovado em 14/10/2015 